\title{
Olumlu Çocukluk Yaşantıları Ölçeği: Türkçe Geçerlik ve Güvenirlik
}

\section{Çalışması}

\author{
Positive Childhood Experiences Scale: Turkish Validity and Reliability Study
}

\section{İlhan ÇíÇEK[1] Veysi ÇERİ[2]}

Başvuru Tarihi: 7 Ağustos 2021

Bu çalışmanın amacı, Olumlu Çocukluk Yaşantıları Ölçeği'nin Türkçe'ye uyarlanması ve geçerlik ve güvenirliğinin test edilmesidir. Araştırma, yaşları 18-56 arasında değișen, 252 kadın ve 198 erkek olmak üzere 450 yetișkin üzerinde yapılmıștır $(M=31.61, S D=$ 4.79). Bu bağlamda, ilk olarak ölçeğin dilsel eşdeğerliliğine bakıldı. Uzmanlardan alınan görüşler sonucunda ölçeğin dilsel eşdeğerliğe sahip olduğu değerlendirilmiştir. Sonrasında alan uzmanlarından ölçeğin kapsam geçerliliğine ilişkin görüş alındı. Değerlendirmeye katılan alan uzmanlarının çoğunluğu, ölçeğin kapsam geçerliliğinin yeterli düzeyde olduğu görüşünü dile getirdiler. Ölçeğin yapı geçerliliği, açımlayıcı ve doğrulayıcı faktör analizleri ile yapıldı. Ölçeğin Açımlayıcı faktör analizinde, ölçeğin tek faktörlü, Cronbach alfa katsayısının .78 olduğu ve toplam varyansın \%45,22'sini açıkladığı ortaya çıkmıștır. DFA'dan elde edilen sonuçlar, ölçeğin uyum iyiliği değerlerinin büyük kısmının iyi uyum değerlerine sahip olduğu ve orjinalinde olduğu gibi tek faktörlü olarak doğrulandığı saptanmıştır. Sonuç olarak, elde edilen bulgulara göre, Olumlu Çocukluk Yaşantıları Ölçeği'nin Türkçe formunun tek boyutlu ve geçerli ve güvenilir bir ölçme aracı olduğunu göstermektedir. Literatürde olumlu çocukluk yaşantılarıyla ilgili sınırlı sayıda ölçeğin bulunmasından dolayı, Türkçe uyarlaması yapılan bu ölçeğin alana katkı sağlayacağı ve önemli bir boşluğu dolduracağı değerlendirilmektedir. Olumlu çocukluk yașantılarının etkisine yönelik yetişkinlik dönemindeki farklı yaş gruplarında çalışmaların (depresyon, stres, psikolojik iyi oluş, anlamlı yașam vb.) yapılması yerinde olacağı düşünülmektedir. Araștırmanın sonuçları, ilgili literatür çerçevesinde tartışılmıştır.

Anahtar Kelimeler: olumlu çocukluk yaşantıları ölçeği, geçerlik, güvenirlik, pozitif psikoloji

Received Date:7 August 2021

ABSTRACT

Accepted Date:21 September 2021

The aim of this study is to adapt the Positive Childhood Experiences Scale into Turkish and to test its validity and reliability. The study was conducted on 450 adults, 252 women and 198 men, whose ages range from 18 to $56(M=31.61, S D=4.79)$. In this context, initially, the linguistic equivalence of the scale was examined. In the light of the views taken from experts, it was evaluated that the scale had linguistic equivalence. Then, opinions on the content validity of the scale were obtained from the field experts. A great majority of the field experts who participated in the evaluation expressed the opinion that the content validity of the scale was sufficient. Construct validity of the scale was carried out with exploratory and confirmatory factor analyses. In the exploratory factor analysis of the scale, it was revealed that the scale had one factor, the Cronbach's alpha coefficient was .78, and it explained 45,22\% of the total variance. The results obtained from CFA showed that most of the goodness of fit values of the scale had good fit values and it was confirmed as a single factor as in the original scale. In conclusion, the findings show that the Turkish form of the Positive Childhood Experiences Scale is a single dimension dimensional and valid and reliable measurement tool. Due to the limited number of scales related to positive childhood experiences in the literature, it is considered that this scale, which has been adapted into Turkish, will contribute to the field and fill an important gap. It is thought that it would be appropriate to conduct studies (depression, stress, psychological well-being, meaningful life, etc.) in different age groups in adulthood on the effect of positive childhood experiences. The results of the research were discussed within the framework of the relevant literature.

Keywords: positive childhood experiences, validity, reliability, positive psychology 


\section{GíRiș}

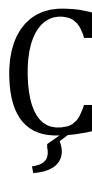
ocukluk döneminde yaşanılan yaşantılar, bireyin sonraki dönemlerdeki davranışları üzerinde ciddi etkiler bırakmaktadır (Burger, 2006). Bireyin yaşam boyu gelişiminde çocukluk yaşantılarının niteliği öne çıkan konular arasındadır. Bu bağlamda literatürde birçok kuramcı, çocukluk yaşantılarını merkeze almışlar (Cervone ve Pervin, 2018; Çiçek, 2020). Öte yandan çocukluk yaşantıları temelli araştırmalarının çoğunluğunun odağında olumsuz çocukluk yaşantılarının yer aldığı görülmektedir (Bonanno, 2004; Doğan ve Aydın, 2020; Domhardt vd., 2014; Huh vd., 2017; Kayman vd., 2021; Kaynar ve Er, 2015; Terock vd., 2016). Olumlu çocukluk yaşantıları, bireyin güvenli bir ortamda büyümesi, sosyal katılım firsatlarına sahip olması, ebeveynleriyle olumlu bir etkileşim içerisinde büyümesi ve duygusal yeterlilikleri öğrenmesi sürecidir. Ayrıca çocuk-ebeveyn arasında kaliteli ve saydam bir ilişkinin olmasıdır (MasoomAli vd, 2020; Özaslan vd., 2021; Sege ve Browne, 2017). Çocukluk yaşantılarını olumlu koşullarda geçiren bireylerin ilerleyen yıllarda bu deneyimlerin olumlu yansımaları görülmektedir (Alshehri, Yıldırım ve Vostanis, 2020; Bethell vd., 2019; Oliviera vd.., 2016; Özaslan ve Yıldırım, 2021). Olumlu çocukluk yaşantıları, bireylerin ilerleyen dönemlerde psikolojik olarak daha güçlü olmalarını ve kendi benliklerine ilişkin pozitif bir düşünce geliştirmelerini sağlamaktadır. Nitekim araştırmalar, olumlu çocukluk yaşantılarının, benlik saygısı ve psikolojik sağlamlık (Çiçek, 2020; Kocatürk ve Çiçek, 2021), mutluluk (Coffey, Warren ve Gottfried, 2015), psikolojik sağlamlık ve algllanan mutluluk (Doğan ve Yavuz, 2020) ve fiziksel sağlık (Chopik ve Edelstein, 2019) arasında pozitif bir ilişki olduğunu göstermiștir. Richards ve Huppert (2011) yaptıkları araştırmada, olumlu çocukluk yaşantılarının iyi oluş üzerinde uzun süreli etkilerinin olduğunu ortaya çıkartmışlar. Ayrıca olumlu çocukluk yaşantıları diğer olumsuz çevre koşullarının bireylerin yaşamları üzerindeki olası olumsuz etkilerini azaltmada önemli bir işlev görmektedir (Masoon Ali vd., 2020; Yıldırım vd., 2020). Sonuç olarak olumlu çocukluk yaşantılarının bireylerin daha sonraki yıllardaki yaşantıları üzerinde olumlu sonuçlar doğurmaktadır (Bethell vd., 2019; Kocatürk ve Çiçek, 2021). Bireyin çocukluk döneminde olumsuz yaşantılar geçirmemiş olması kadar, yeteri kadar olumlu yaşantılar deneyimlemesi de büyük önem arz etmektedir. Bu boyutuyla bakıldığında bireyin çocukluk dönemindeki olumsuz yaşantılarının araştırıldığı kadar, olumlu yaşantılarının da araştırılması, bireyin psikolojik durumunun daha objektif ele alınması açısından faydalı olacağı varsayılmaktadır (Arslan ve Yıldırım, 2021; Doğan ve Aydın, 2020; Kocatürk ve Çiçek, 2021). Bu düşüncelerden yola çıkılarak bu araştırmanın amacı, Bethell vd. (2019) tarafından geliştirilen Olumlu Çocukluk Yaşantıları Ölçeği'nin Türk kültürüne uyarlanmasıdır. 


\section{Araştırmanın Önemi}

Literatüre bakıldığında ülkemizde olumlu çocukluk yaşantılarını ölçen ölçme araçlarının çok sınırlı olduğu gözlemlenmektedir. Türkiye'de olumlu çocukluk yaşantıları ile ilgili ilk ölçme aracının geliştirilmesi Doğan ve Aydın (2020) tarafından yapılmıştır. Ölçme aracı, bireylerin on bir yaş öncesi dönemdeki olumlu yaşantılarını ölçmektedir. Dolayısıyla Doğan ve Aydın (2020) tarafından geliştirilen ölçme aracı, çocukluk dönemindeki belli bir aralığı kapsamaktadır. $\mathrm{Bu}$ durum, bu ölçme aracının bir sınırlılığı olarak değerlendirebilir. Türkçe’ye uyarlamasını yaptığımız Olumlu Çocukluk Yaşantıları Ölçeği ise bireyin on sekiz yaş öncesi dönemde geçirdiği olumlu yaşantıları kapsamaktadır. Bu amaç doğrultusunda uyarlaması yapılan bu ölçeğin alanda büyük bir boşluğu dolduracağı ve olumlu çocukluk yaşantıları ile bireyin yetişkinlik dönemindeki farklı değişkenlerle (yaşamın anlamı, psikolojik sağlamlık, mutluluk, umut, sosyal destek, iyi oluş, öz yeterlilik, kişilik özellikleri vb.) nasıl bir ilişki olduğu konusunun incelenmesinin anlamlı olacağı değerlendirilmektedir.

\section{Araştırmanın Amacı}

$\mathrm{Bu}$ araştırmanın amacı Bethell vd. (2019) tarafından geliştirilen Olumlu Çocukluk Yaşantıları Ölçeği'nin Türkçe uyarlamasının yapılmasıdır.

\section{YÖNTEM}

\section{Araștırmanın Modeli}

Çalışmanın yöntemi, ilişkisel tarama modelidir. Literatürde tarama modeli, bir grubun belirli özelliklerini ortaya çıkartmak için verilerin toplanmasını hedefleyen çalışmalar şeklinde tanımlanmaktadır (Büyüköztürk vd., 2014).

\section{Çalışma Grubu}

Çalışma grubunun oluşturulmasında veri setinin faktör analizindeki uygunluğu dikkate alınmıştır. Zira ölçek uyarlama çalışmalarında örneklem büyüklüğünün, tahmin edilecek parametre sayının en az 10 katı örneklem büyüklügüne ulaşılması ve araştırma için gerekli olan örneklem büyüklügüunün en az 150 olması gerekmektedir (Gürbüz, 2018; Huck, 2012; Pallant, 2007). Bu şartlara bağlı olarak 7 madden oluşan Olumlu Çocukluk Yaşantıları Ölçeği için 450 kişiye ulaşılmıştır. Uyarlama çalışmasında veriler, üç farklı çalışma grubundan toplanmıştır. Birinci çalışma grubu İngilizcesi iyi düzeyde olan 20 akademisyenden oluşmaktadır. Bu gruptan toplanan veri ölçeğin dilsel açıdan eşdeğerliliğini test etmek için kullanılmıştır. İkinci çalışma grubu 220 kişiden oluşmaktadır. Bu gruptan toplanan veriler, Açımlayıcı Faktör Analizi 
(AFA)'inde kullanılmıştır. Üçüncü çalışma grubu 230 kişiden oluşmaktadır. Bu gruptan toplanan veriler, Doğrulayıcı Faktör Analizinde (DFA) kullanılmıştır.

Tablo 1

Katılımcılara ilişkin bilgiler

\begin{tabular}{|c|c|c|c|c|c|c|c|}
\hline \multirow{2}{*}{ Değişken } & \multirow{2}{*}{ Grup } & & & \multicolumn{2}{|c|}{ AFA } & \multicolumn{2}{|c|}{ DFA } \\
\hline & & Yass & $S S$ & $n$ & $\%$ & $n$ & $\%$ \\
\hline \multirow{3}{*}{ Cinsiyet } & Kadın & & & 125 & 56.8 & 127 & 54.5 \\
\hline & Erkek & & & 95 & 43.2 & 103 & 45.5 \\
\hline & Toplam & 31.61 & 8.79 & \multicolumn{2}{|c|}{220} & \multicolumn{2}{|c|}{230} \\
\hline
\end{tabular}

\section{Veri Toplama Araçları}

Olumlu Çocukluk Yaşantıları Ölçeği (OÇYÖ). Araştırmada, Bethell ve diğerleri (2019) tarafından geliştirilen Olumlu Çocukluk Yaşantıları Ölçeği (OÇYÖ) kullanılmıştır. 7 maddeden oluşan ölçek, 5'li Likert tipi (1 Hiçbir zaman -5 Her zaman) bir ölçektir. Ölçekte ters puanlanan madde bulunmamaktadır. Ölçekten en az 7, en yüksek 35 puan alınmaktadır. Ölçekten alınan yüksek puanlar, bireylerin çocukluk dönemlerinde daha fazla olumlu yaşantı geçirdiklerini göstermektedir. Olumlu Çocukluk Yaşantıları Ölçeği, bireylerin 18 yaşından önceki olumlu yaşantılarını ölçmektedir. Bu bağlamda ölçek, 18 yaş ve üzeri kişiler üzerinde uygulanmaktadır.

\section{Veri Toplama Süreci}

Çalışmanın verileri 19 Şubat ile 5 Mart 2021 tarihleri arasında sosyal medya platformları üzerinde online olarak toplanmıştır. Katılımcılara çalışma hakkında gerekli bilgilendirme yapılarak, katılımcılara herhangi bir ücret ödenmemiştir.

\section{Verilerin Analizi}

Verilerin analizinde SPSS 24 ve AMOS 21 kullanılmıştır. OÇYÖ’nin geçerliliği, kapsam ve yapı geçerliliği yöntemleri kullanılarak değerlendirilmiştir. Çalışmada, ölçeğin kapsam geçerliliği için alan uzmanlarından görüş alınmıştır. Yapı geçerliliğini test etmek için Açımlayıcı Faktör Analizi (AFA) ve Doğrulayıcı Faktör Analizi (DFA) yapılmıştır. Ölçeğin faktörlenebilirliliğini test etmek için Bartlett'in küresellik testi, örneklem yeterliliğini ölçmek için Kaiser-Meyer-Olkin (KMO) testi yapılmıştır. Ölçeğin güvenirlik analizine Cronbach's alfa ve Spearman-Brown güvenilirlik katsayılarıyla bakılmıştır.

\section{Etik Onay}

Araştırmanın yürütülmesi için Batman Üniversitesi Etik Kurul'undan 2021/02-13 sayıyla etik kurul izni alınmıștır. 


\section{BULGULAR VE YORUM}

\section{Dil ve Kapsam Geçerliğine İlişkin Bulgular}

Ölçeğin kapsam geçerliliğini sınamak için on akademisyenin görüşüne başvurulmuştur. Ölçeklerin kapsam geçerliliği için minimum beş uzman görüşü yeterli görülmektedir (Lawshe, 1975). Bir maddenin ölçekte yer almasına karar vermek için uzmanların yarısından fazlasının ilgili madde için "gerekli" olduğunu ifade etmesi yeterlidir (Alpar, 2014; Lawshe, 1975; Sürücü ve Maslakçı, 2020). Araştırmada görüşlerine başvurulan akademisyenlerin çoğunluğu tüm maddeler için "gerekli" şeklinde değerlendirme yaptıklarından araştırmada kullanılan ölçeğin kapsam geçerliliğine sahip olduğu sonucuna varılmıştır. Ölçek, İngilizceye hâkim 10 akademisyenin birlikte çalışması ile Türkçeye çevrilmiştir. İki akademisyen tarafından Türkçe metin İngilizce metne tekrar çevrilmiştir. İngilizce ilk metin ile son metin arasında farklılığın olmadığı görülmüştür. Asıl uygulamadan önce ölçek, 20 alan uzmanı üzerinde uygulanmıştır. Sonuç olarak, ölçeğin Türkçe çevirisinin İngilizce formu ile tutarlı olduğu, aralarındaki korelasyonun anlamlı olduğu (p<.001) ve ölçek maddelerinin anlaşılır olduğu ortaya çıkmıştır.

\section{Yapı Geçerliğine İlişkin Bulgular}

OÇYÖ’nin Türkçe formunun faktör yapısını incelemek amacıyla Açımlayıcı Faktör Analizi (AFA) ve Doğrulayıcı Faktör Analizi (DFA) uygulanmıştır.

\section{Açımlayıcı Faktör Analizi (AFA)}

Ölçeğin güvenirliğini test etmek için Cronbach alfa katsayısına ve Spearman-Brown güvenirlik katsayına bakılmıștır. Ölçeğin Cronbach alfa katsayısı ,78'dir. Spearman-Brown Güvenirlik katsayısı (ikiye bölünmüş yöntem) ise ,71'dir. Çalışmada ayrıca Olumlu Çocukluk Yaşantıları Ölçeği'ne ait korelasyon ve madde toplam istatistiklerine bakılmıştır. Ölçek maddelerine ait korelasyon katsayıları ve madde-toplam istatistik analiz sonuçları tablo halinde verilmiştir (Tablo 2). Analiz sonuçlarına göre maddeler arasındaki korelasyon katsayılarının,271 -,597 arasında olduğu görülmüştür. Cronbach alfa katsayısının ve Spearman-Brown güvenirlik katsayısının ,70'in üzerinde olması ölçeğin orta düzeyde bir güvenirliğe sahip olduğu değerlendirilmektedir (Alpar, 2014; Büyüzöztürk, 2013). 


\section{Tablo 2}

Olumlu Çocukluk Yaşantıları Ölçek maddelerine ait korelasyon katsayıları

\begin{tabular}{|c|c|c|c|c|c|c|c|}
\hline Ölçekte Yer Alan Maddeler & 1 & 2 & 3 & 4 & 5 & 6 & 7 \\
\hline $\begin{array}{l}\text { OÇYÖ 1. Ailenizle. duygularınız hakkında hangi sıklıkta } \\
\text { konuşabiliyordunuz? }\end{array}$ & 1 & & & & & & \\
\hline $\begin{array}{l}\text { OÇYÖ 2. Zor zamanlarda ailenizin yanınızda olduğunu hangi sıklıkta } \\
\text { hissediyordunuz? }\end{array}$ & $.59^{*}$ & 1 & & & & & \\
\hline $\begin{array}{l}\text { OÇYÖ 3. Çocukluk döneminizin ne kadarında sizi evinizde güvende ve } \\
\text { korunmuş hissettiren bir yetişkin vardı? }\end{array}$ & $.29^{*}$ & $.56^{*}$ & 1 & & & & \\
\hline $\begin{array}{l}\text { OÇYÖ 4. Çevrenizde hangi sıklıkta anne ve babanızın dışında sizinle } \\
\text { gerçekten ilgilenen en az iki yetişkin oldu? }\end{array}$ & $.35^{*}$ & $.35^{*}$ & $.32^{*}$ & 1 & & & \\
\hline $\begin{array}{l}\text { OÇYÖ 5. Arkadaşlarınız tarafından ne kadar sık desteklendiğinizi } \\
\text { hissediyordunuz? }\end{array}$ & $.34^{*}$ & $.39^{*}$ & $.31^{*}$ & $.31^{*}$ & 1 & & \\
\hline $\begin{array}{l}\text { OÇYÖ 6. Hangi sıklıkta kendinizi okuduğunuz liseye ait } \\
\text { hissediyordunuz? }\end{array}$ & $.28^{*}$ & $.29^{*}$ & $.28^{*}$ & $.27^{*}$ & $.44^{*}$ & 1 & \\
\hline $\begin{array}{l}\text { OÇYö 7. Geleneksel ve toplu etkinliklere katılmaktan hangi sıklıkta keyif } \\
\text { alırdınız? }\end{array}$ & $.34^{*}$ & $.43^{*}$ & $.32^{*}$ & $.34^{*}$ & $.37^{*}$ & $.38^{*}$ & 1 \\
\hline
\end{tabular}

Faktör analizi için veri yapısının uygunluğunu ve faktörlenebilirliğini belirlemek üzere yapılan testlerde KMO katsayısı,77 olarak belirlenmiştir ve Bartlett'in küresellik testi sonucu anlamlı $(\chi 2=409,254 ; p<, 000)$ bulunmuştur. Faktör sayısını belirlemek için, yamaç birikinti grafiğinden yararlanılmıștır (Șekil 1). Șekil 1 incelendiğinde; özdeğeri 1'den büyük bir faktörün olduğu görülmektedir. Ölçeğin faktör öz değeri: 3,138'dir. Tek faktörlü olarak çıkan ölçek, toplam varyansın \%45,22'lik kısmını açıklamaktadır. Toplam varyansı açıklama oranı sosyal bilimlerde, yüzde \%40 üstü yeterli kabul edilmektedir (Alpar, 2014; Büyüköztürk, 2013). Bu ölçüte göre, ölçeğin gerekli şartları sağladığı söylenebilir. Son adım olarak, ölçeğin faktör yapısının belirlenmesi işlemidir. Bu doğrultuda, faktör yük ve ortak faktör yük değerlerine bakılmıştır. Ortak faktör yüklerinin $>.20$ (Tabachnick \& Fidell, 2013) ve faktör değerlerinin $>.45$ (Büyüköztürk, 2013) olması dikkate alınmıştır. Tablo 3'te görüldüğü gibi faktör yükleri incelendiğinde maddelerin ortak faktör yüklerinin .33 ile .63 arasında değiştiği ve faktör yük değerleri ise .58 ile .79 değişmektedir. Sonuç olarak, bütün maddelerin birinci faktöre yüksek düzeyde yüklenebildiği görülmüştür. 


\section{Tablo 3}

Olumlu Çocukluk Yaşantıları Ölçeği'nin betimsel istatistikleri, güvenilirlik ～katsayıları açımlayıcı faktör analiz sonuçları

\begin{tabular}{|c|c|c|}
\hline Ölçekte yer alan maddeler & $\begin{array}{c}\text { Faktör } \\
\text { Yükü }\end{array}$ & $\begin{array}{c}\text { Ortak } \\
\text { Faktör } \\
\text { Yükü } \\
\end{array}$ \\
\hline OÇYÖ 1. Ailenizle, duygularınız hakkında hangi sıklıkta konuşabiliyordunuz? & .69 & .48 \\
\hline $\begin{array}{l}\text { OÇYÖ 2. Zor zamanlarda ailenizin yanınızda olduğunu hangi sıklıkta } \\
\text { hissediyordunuz? }\end{array}$ & .79 & .63 \\
\hline $\begin{array}{l}\text { OÇYö 3. Çocukluk döneminizin ne kadarında sizi evinizde güvende ve korunmuş } \\
\text { hissettiren bir yetişkin vardı? }\end{array}$ & .66 & .43 \\
\hline $\begin{array}{l}\text { oÇYÖ 4. Çevrenizde hangi sıklıkta anne ve babanızın dışında sizinle gerçekten } \\
\text { ilgilenen en az iki yetişkin oldu? }\end{array}$ & .58 & .33 \\
\hline OÇYÖ 5. Arkadaşlarınız tarafından ne kadar sık desteklendiğinizi hissediyordunuz? & .67 & .46 \\
\hline OÇYÖ 6. Hangi sıklıkta kendinizi okuduğunuz liseye ait hissediyordunuz? & .60 & .47 \\
\hline OÇYÖ 7. Geleneksel ve toplu etkinliklere katılmaktan hangi sıklıkta keyif alırdınız? & .64 & .42 \\
\hline Cronbach-alpha Güvenirlik Katsayısı & .78 & \\
\hline Spearman-Brown Güvenirlik Katsayısı & .71 & \\
\hline Öz Değer & 3,138 & \\
\hline Açıklanan Varyans (\%) & 45,22 & \\
\hline Barttlet'in Küresellik Testi p değeri: & .000 & \\
\hline Kaiser-Mayer-Olkin (KMO) & .78 & \\
\hline
\end{tabular}

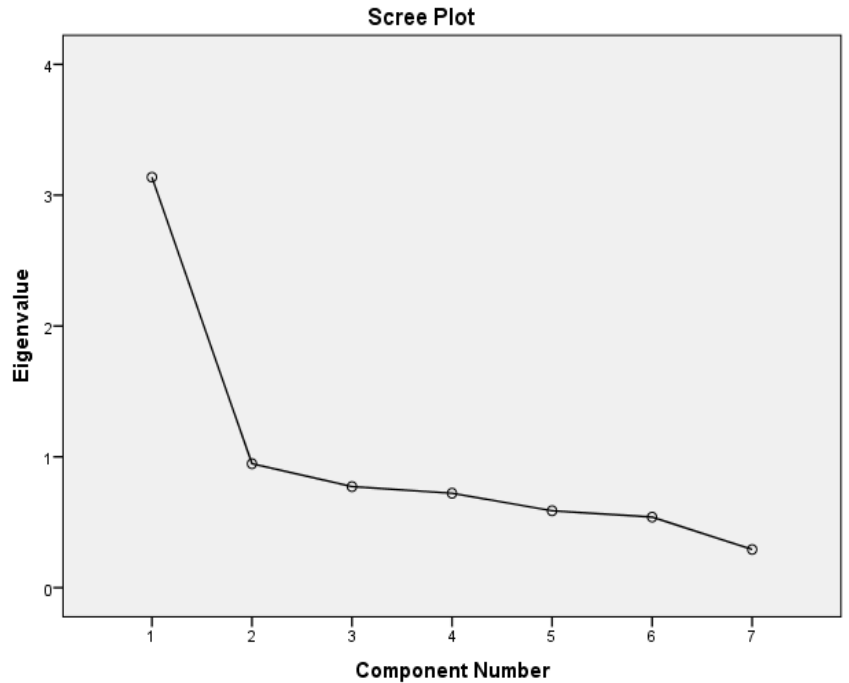

Şekil 1.Olumlu Çocukluk Yaşantıları Ölçeği'nin yamaç birikinti grafiği

\section{Doğrulayıcı Faktör Analizi Bulguları (DFA)}

Ölçek geliştirmede ve uyarlamda açımlayıcı faktör analizi ile birlikte doğruylayıcı faktör analizinin yapılması gerekmektedir (Huck, 2012). Bu yüzden ölçeğin tek boyutlu yapısı DFA ile test edildi. DFA'ya geçilmeden önce verilerin normal dağılımı test edilmiştir. Değişkenlere ait basıklık (kurtosis) ve çarpıklık (skewness) değerlerinin \pm 1 değerleri arasında ve çoklu basıklık kritik değerinin (multivariate kurtosis critical value) 10'un altında $(3,227)$ olduğu görülmüştür. $\mathrm{Bu}$ sonuçlara göre verilerin normal dağıldığı söylenebilir (Gürbüz, 2019). Doğrulayıcı faktör analizinde, ilk olarak uyum iyiliği değerlerine bakıldı. Sonrasında faktör yapısı analiz edildi. 
Araştırmada, aşağıda yer alan model uyum değerleri temel alındı. Bu değerler; $\chi 2$ / df (serbestlik derecesi), tahmin hatalarının ortalamasının karekökü (Root Mean Square Error of Approximation-RMSEA), karşılaştırmalı uyum indeksi (Comparative Fit Index-CFI), fazlalık uyum indeksi (Incremental Fit Index-IFI), iyilik uyum indeksi (Goodness of Fit Index-GFI), hata kareleri ortalamasının karekökü (Root Mean Square Residual-RMR) ve normlaştırılmış uyum indeksi (Normed Fit Index-NFI)'dir. Revizyon öncesi uyum değerleri ( Ki-kare / sd: 3.30, RMSEA: .079, NFI: .89, IFI: .92, CFI: .92, GFI: .95, RMR: .83) olarak bulunmuştur. Uyum iyiliği indekslerine bakıldıktan sonra modifikasyon (düzeltme) indeksleri incelenmiştir. Araştırmada kovaryanslara ilişkin düzeltme indeks değerlerinden yola çıkılarak gerekli düzeltmeler yapılmıștır. Kovaryanslara ilişkin düzeltmelerde modelde yer alan değişkenlerin denekler tarafından neredeyse aynı şekilde algılanan maddelerin birleştirilmesini sağlar (Gürbüz, 2019). Düzeltme yapılırken dikkat edilmesi gereken belli hususlar vardır. Bu hususlar; düzeltmelerin teker teker yapılması ve eşik değerlere ulaşıldığında başka düzeltme yapılmamasıdır. Ayrıca 6 ile 11 maddeden oluşan ölçeklerde 2'den fazla düzeltme yapılmaması önerilmektedir (Johnson, 2016; Meydan ve Şeşen, 2011). Ölçekte yer alan OÇYÖ1-OÇYÖ3 maddeleri ile OÇYÖ5-0ÇYÖ6 maddelerinin birleşim modifikasyonları yapıldıktan sonra ölçeğin beklenen uyum değerlerinde olduğu tespit edilmiştir (Schermelleh-Engel, Moosbrugger ve Müller, 2003).

\section{Tablo 4}

Uyum iyiliği indeksleri

\begin{tabular}{lllll}
\hline İndeks & İyi uyum & Kabul edilebilir uyum & Sonuç & Değerlendirme \\
\hline $\mathrm{x}^{2}$ & - & - & & - \\
Ki-kare / sd & $0 \leq \mathrm{x}^{2} / \mathrm{df} \leq 2$ & $2 \leq \mathrm{x}^{2} / \mathrm{df} \leq 3$ & 2,25 & Kabul edilebilir \\
RMSEA & $0 \leq \mathrm{RMSEA} \leq .05$ & $.05 \leq \mathrm{RMSEA} \leq .08$ & .076 & Kabul edilebilir \\
$\mathrm{NFI}$ & $.95 \leq \mathrm{NFI} \leq 1.00$ & $.90 \leq \mathrm{NFI} \leq .95$ & .96 & İyi uyum \\
$\mathrm{IFI}$ & $.97 \leq \mathrm{IFI} \leq 1.00$ & $.95 \leq \mathrm{NNFI} \leq .97$ & .96 & Kabul edilebilir \\
$\mathrm{CFI}$ & $.97 \leq \mathrm{CFI} \leq 1.00$ & $.95 \leq \mathrm{CFI} \leq .97$ & .97 & İyi uyum \\
GFI & $.95 \leq \mathrm{GFI} \leq 1.00$ & $.90 \leq \mathrm{GFI} \leq .95$ & .97 & İyi uyum \\
AGFI & $.90 \leq \mathrm{AGFI} \leq 1.00$ & $.85 \leq \mathrm{AGI} \leq .90$ & .92 & İyi uyum \\
RMR & $.05 \leq \mathrm{RMR} \leq .07$ & $.08 \leq \mathrm{GFI} \leq .95$ & .076 & İyi uyum \\
\hline
\end{tabular}

Uyum iyiliği indeksleri için "kabul edilebilir" değeler, "iyi uyum" değerleri ve modele ait uyum değerleri tablo halinde verilmiştir (Tablo 4). Analiz sonuçlarına göre RMSEA (.076), $\chi 2 / \mathrm{df}$ (2,25), IFI (.96) v değerinin "kabul edilebilir" uyum düzeyinde, diğer indeks değerlerin ( GFI: .97; CFI: .97; RMR: .76 ve NFI: .96) ise "iyi uyum" düzeyinde olduğu belirlenmiştir. Ölçeğin son şekline ait DFA modeli Şekil 2'de gösterilmiştir. Sonuç olarak, Olumlu Çocukluk Yaşantıları Ölçeği'nin tek faktörlü olarak doğrulandığı saptanmıştır. 


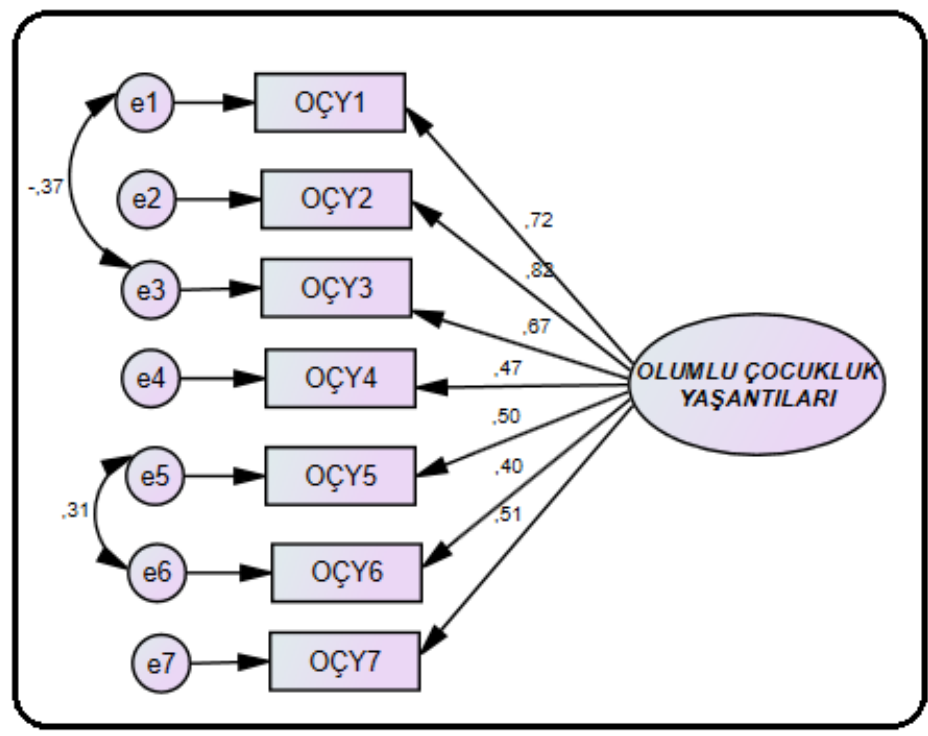

Şekil 2. Olumlu Çocukluk Yaşantıları Ölçeği'nin Doğrulayıcı Faktör Analizi

\section{TARTIŞMA, SONUÇ VE ÖNERÍLER}

Bu çalışmanın amacı, bireylerin olumlu çocukluk yaşantılarını ölçen, Bethell ve diğerleri (2019) tarafından geliştirilen ve 7 maddeden oluşan "Olumlu Çocukluk Yaşantıları Ölçeği'nin" Tükçe'ye uyarlanmasıdır. Türkçe uyarlaması yapılan bu ölçeğin alanda büyük bir boşluğu dolduracağı değerlendirmektedir. Zira ülkemizde olumlu çocukluk yaşantılarını ölçen sınırlı sayıda ölçme aracının olduğu ve bu ölçme araçlarının çocukluk döneminin belli bir aralığına odaklandıkları (Akın vd., 2013; Doğan ve Aydın, 2020) ya da çocukluk yaşantılarını daha çok sosyal ilişkiler perspektifinde ölçtükleri görülmektedir (Manap, 2015). Öte yanda uyarlaması yapılan Olumlu Çocukluk Yaşantıları Ölçeği ise çocukluk döneminin tümünü kapsayan -on sekiz yaş öncesi-bir ölçme aracı olması bakımından diğer ölçeklerden ayrışmaktadır. Dolayısıyla bu ölçeğin yeni çalışmalara kaynaklık edeceği ve çocukluk döneminde yaşanılan olumlu deneyimlerin sonuçlarının ne olduğu konusunda diğer psikolojik değişkenlerle inceleme fırsatı vereceği düşünülmektedir.

Analiz sonuçları, ölçeğin orijinalinde olduğu gibi tek faktörlü bir yapıda olduğunu göstermiştir. Ölçeğin uyarlama çalışmasında öncelikle dilsel eşdeğerlilik uygulamaları yapılmış. Dilsel eşdeğerlik sonuçları, ölçeğin orijinal formu ile Türkçe formu arasında anlamlı bir ilişkinin olduğunu göstermiştir. Dilsel eşdeğerlik analizinden sonra, ölçeğin kapsam geçerliliği ile ilgili alan uzmanlarından görüş alınmıştır. Alan uzmanlarının olumlu görüş bildirmelerinden sonra, ölçeğin yapı analizi için gerekli istatistiki çalışmalar yapıldı. Ölçeğin yapı geçerliliği, AFA ve DFA ile incelenmiştir. AFA için 220 yetişkinden elde edilen verilerle analiz edilmiştir. Ölçeğin faktör 
analizinin uygunluğu için KMO örneklem uygunluk katsayısına bakılmıștır. Ölçeğin KMO örneklem uygunluk katsayısı (.78) ve Barlett Sphericity testi değeri (403.906, p<.000) yüksek uygunlukta bulunmuştur. Ölçeğin Cronbach alfa değeri .78 olarak hesaplanmıştır. Tek faktörlü olan OÇYÖ’nin, toplam varyansın \%45.22'sini açıkladığı ortaya çıkmıştır. Ayrıca bütün ölçek maddelerinin faktör yüklerinin .30'dan yüksek olduğu saptanmıştır (Büyüköztürk, 2013). DFA, OÇYÖ'nin orijinal formunun faktör yapısının Türkçe örnekleminde doğrulanıp doğrulanmayacağını ortaya koymak amacıyla 230 yetişkinden elde edilen veriler ile yapılmıştır. Sonuçlar, AFA'da olduğu gibi ölçeğin tek boyutlu olduğu ve uyum iyiliği değerlerinin kabul edilebilir sınırları içerisinde olduğunu göstermiştir. Dolayısıyla Olumlu Çocukluk Yaşantıları Ölçeği'nin Türkçe uyarlanmasının uygulanmasında herhangi bir sakıncanın olmadığı ve yeterli geçerlik ve güvenirliğe sahip olduğu saptaması yapılabilir. Araștırmacıların pozitif psikoloji il ilgili yeni ölçeklerin geliştirilmesine dönük çalışmalar yapabilirler. 


\section{KAYNAKÇA}

Alpar, R. (2014). Spor sağlık ve eğitim bilimlerinden örneklerle uygulamalı istatistik ve geçerlik güvenirlik. Detay Yayıncılık.

Alshehri, N. A., Yildirim, M., \& Vostanis, P. (2020). Social Support and Mental Health Problems. Arab Journal of Psychiatry, 31(2), 130-143.

Akın, A., Uysal, R. ve Çitemel, N. (2013). Çocukluk Dönemi Mutluluk/Huzur Anıları Ölçeği'nin Türkçe formunun geçerlik ve güvenirlik çalışması. Uludağ Üniversitesi Eğitim Fakülte Dergisi, 26(1), 71-80.

Arslan, G., \& Yıldırım, M. (2021). Okulda Mutluluğun Ölçülmesi ve Desteklenmesi. In Arslan G. \& Yıldırım, M. (Eds), Okulda Pozitif Psikoloji: Kuramdan Uygulamaya (pp. 5-15). Pegem Akademi.

Axelsson R. (2000). The organizational pendulum: Healthcare management in Sweden 18651998. Scandinavian Journal of Public Health, 28(1), 47-53. https://doi.org/10.1177/140349480002800109

Bethell, C., Jones, J., Gombojav, N., Linkenbach, J., \& Sege, R. (2019). Positive Childhood Experiences and Adult Mental and Relational Health in a Statewide Sample. JAMA Pediatrics, 173(11), e193007. https://doi.org/10.1001/jamapediatrics.2019.3007

Bonanno, G. A. (2004). Loss, Trauma, and Human Resilience: Have We Underestimated the Human Capacity to Thrive After Extremely Aversive Events? American Psychologist, 59(1), 20-28. https://doi.org/10.1037/0003-066x.59.1.20

Burger, J. M. (2006). Kişilik; psikoloji biliminin insan doğasına dair söyledikleri. Kaknüs Yayınları.

Büyüköztürk Ș. (2013). Sosyal bilimler için veri analizi el kitabı. Pegem Akademi.

Büyüköztürk, Ş., Demirel, F., Erkan-Çakmak, Ö., Kılıç-Çakmak, E., \& Karadeniz, Ş. (2014). Bilimsel araștırma yöntemleri. Pegem Akademi Yayınları.

Cervone, D., \& Pervin, L. A. (2018). Personality: Theory and research (14th ed.). Jefferson City, MO: John Wiley \& Sons.

Chopik, W. J., \& Edelstein, R. S. (2019). Retrospective memories of parental care and health from mid-to late life. Health Psychology, 38(1), 84-93. https://doi.org/10.1037/hea0000694

Coffey, J. K., Warren, M. T., \& Gottfried, A. W. (2015). Does infant happiness forecast adult life satisfaction? Examining subjective well-being in the first quarter century of life. Journal of Happiness Studies, 16(6), 1401-1421. https://doi.org/10.1007/s10902-014-9556$\mathrm{x}$

Çiçek, İ. (2020). Çocuk psikolojisi ve ruh sağlığı. Eğiten Kitabevi.

Dogan, T., \& Aydin, F. T. (2020). The Development of the Positive Childhood Experiences Scale/Olumlu cocukluk Yaşantıları Ölçeği'nin Geliştirilmesi. HAYEF: Journal of Education, 17(1), 1-21. https://doi.org/10.5152/hayef.2020.1925

Doğan, T., \& Yavuz, K. (2020). Yetişkinlerde psikolojik sağlamlık, olumlu çocukluk deneyimleri ve algılanan mutluluk. Psikiyatride Güncel Yaklaşımlar, 12, 312- 330. https://doi.org/10.18863/pgy.750839

Domhardt, M., Münzer, A., Fegert, J. M., \& Goldbeck, L. (2015). Resilience in survivors of child sexual abuse: A systematic review of the literature. Trauma, Violence, \& Abuse, 16(4), 476-493. https://doi.org/10.1177/1524838014557288

Gürbüz S. (2019). AMOS ile yapısal eşitlik modellemesi. Seçkin Yayıncılık.

Hansson, A.-S., Vingård, E., Arnetz, B. B., \& Anderzén, I. (2008). Organizational change, health, and sick leave among health care employees: A longitudinal study measuring stress markers, 
individual, and work site factors. Work \& Stress, 22(1), 69-80. https://doi.org/10.1080/02678370801996236

Huck, S. W. (2012). Reading statistics and research. Pearson Education.

Huh, H. J., Kim, K. H., Lee, H.-K., \& Chae, J.-H. (2017). The relationship between childhood trauma and the severity of adulthood depression and anxiety symptoms in a clinical sample: The mediating role of cognitive emotion regulation strategies. Journal of Affective Disorders, 213, 44-50. https://doi.org/10.1016/j.jad.2017.02.009

Johnson, K. J. (2016). The dimensions and effects of excessive change. Journal of Organizational Change Management, 29(3), 445-459. https://doi.org/10.1108/jocm-11-2014-0215

Kayman, E., Dilsiz, K., Üğücü, G., \& Yiğit, R. (2021). Intörn hemşirelik öğrencilerinin olumsuz çocukluk deneyimleri ile psikolojik iyi oluşları arasındaki ilişki. Adnan Menderes Üniversitesi Sağllk Bilimleri Fakültesi Dergisi, 5(2), 177-185. https://doi.org/10.46237/amusbfd.773826

Kaynar, G., \& Er, N. (2015). Otobiyografik bellekte aşırı genelleme: Çocukluk örselenme yaşantılarının otobiyografik bellek açısından incelenmesi. Türk Psikoloji Dergisi, 30(76), 1-14.

Kocatürk, M., \& Çiçek, İ. (2021). Relationship between positive childhood experiences and psychological resilience in university students: The mediating role of self-esteem. Journal of Psychologists and Counsellors in Schools, 1-12. https://doi.org/10.1017/jgc.2021.16

Lawshe C. H. (1975). A quantitative approach to content validity. Personnel Psychology, 28(4), 563-575. https://doi.org/10.1111/j.1744-6570.1975.tb01393.x

Manap, A. (2015). Çocukluk Yaşantıları Ölçeği'nin geliştirilmesi: Geçerlik ve güvenirlik çalıșması. Uluslararası Sosyal Araştırmalar Dergisi, 8(41), 822-826.

Masoom Ali, S., Yildirim, M., Abdul Hussain, S., \& Vostanis, P. (2020). Self-reported mental health problems and post-traumatic growth among children in Pakistan care homes. Asia Pacific Journal of Social Work and Development, 30(1), 62-76. https://doi.org/10.1080/02185385.2019.1710726

Meydan C. H., \& Şeşen H. (2011). Yapısal eşitlik modellemesi AMOS uygulamaları. Detay Yayıncilık.

Oliveira, S., Ferreira, C., \& Mendes, A. L. (2016). Memórias precoces de calor e segurança e a psicopatologia alimentar: o papel do social safeness e da body appreciation. Psychologica, 2(59), 45-60. https://doi.org/10.14195/1647-8606_59_2_3

Özaslan, A., \& Yıldırım, M. (2021). Internalized stigma and self esteem of mothers of children diagnosed with attention deficit hyperactivity disorder. Children's Health Care, 50(3), 312324. https://doi.org/10.1080/02739615.2021.1891071

Özaslan, A., Yıldırım, M., Güney, E., Güzel, H. Ş., \& İşeri, E. (2021). Association Between Problematic Internet Use, Quality of Parent-Adolescents Relationship, Conflicts, and Mental Health Problems. International Journal of Mental Health and Addiction, 1-17. https://doi.org/10.1007/s11469-021-00529-8

Pallant, J. (2007). Spss survival manual a step by step guide to data analysis using spss for windows. McGraw Hill.

Richards, M., \& Huppert, F. A. (2011). Do positive children become positive adults? Evidence from a longitudinal birth cohort study. The Journal of Positive Psychology, 6(1), 75-87. https://doi.org/10.1080/17439760.2011.536655

Sege, R. D., \& Browne, C. H. (2017). Responding to ACEs with HOPE: Health outcomes from positive experiences. Academic Pediatrics, 17(7), S79-S85. 
Schermelleh-Engel, K., Moosbrugger, H., \& Müller, H. (2003). Evaluating the fit of structural equation models: Tests of significance and descriptive goodness-of-fit measures. Methods of Psychological Research Online, 8(2), 23-74.

Sürücü, L., \& Maslakçl, A. (2020). Validity and reliability in quantitative research. Business \& Management Studies: An International Journal, 8(3), 2694-2726. https://doi.org/10.15295/bmij.v8i3.1540

Tabachnick, B. G., \& Fidell, L. S. (2013). Using multivariate statiscs. Pearson Education.

Terock, J., Van der Auwera, S., Janowitz, D., Spitzer, C., Barnow, S., Miertsch, M., . . G Grabe, H.-J. (2016). From childhood trauma to adult dissociation: The role of PTSD and alexithymia. Psychopathology, 49(5), 374-382.

Yildirim, M., Iqbal, N., Khan, M. M., O’Reilly, M., ve Vostanis, P. (2020). Psychosocial needs and supports for street children in India: Stakeholder perspectives: Psychosocial supports for street children. International Journal of Child Development and Mental Health, 8(2), 1928. 


\section{EXTENDED ABSTRACT}

\section{Introduction}

The experiences lived in childhood leave serious effects on the behavior of the individual in the following periods (Burger, 2006). The quality of childhood experiences is among the prominent issues in the lifelong development of the individual. In this context, many theorists in the literature have centered childhood experiences (Cervone \& Pervin, 2018; Çiçek, 2020). On the other hand, it is seen that the majority of childhood experiences-based studies focus on negative childhood experiences (Bonanno, 2004; Doğan \& Aydın, 2020; Domhardt et al., 2014; Huh et al., 2017; Kayman et al., 2021; Kaynar \& Er, 2015; Terock). et al., 2016). Positive childhood experiences are the process of growing up in a safe environment, having opportunities for social participation, growing up in positive interaction with their parents, and learning emotional competencies. In addition, there is a quality and transparent relationship between the child and the parent (MasoomAli et al., 2020; Özaslan et al., 2021; Sege and Browne, 2017). The positive reflections of these experiences are seen in the following years of individuals who spent their childhood in positive conditions (Alshehri, Yıldırım, \& Vostanis, 2020; Bethell et al., 2019; Oliviera et al., 2016; Özaslan \& Yıldırım, 2021). The aim of this study is to adapt the Positive Childhood Experiences Scale into Turkish.

\section{Method}

The suitability of the data set in factor analysis was taken into account in the creation of the study group. Because, in scale adaptation studies, the sample size should be at least 10 times the number of parameters to be estimated, and the sample size required for the research should be at least 150 (Gürbüz, 2018; Huck, 2012; Pallant, 2007). Depending on these conditions, 450 people were reached for the Positive Childhood Experiences Scale, which consists of 7 items. In the adaptation study, data were collected from three different study groups. The first study group consists of 20 academicians with a good level of English. The data collected from this group was used to test the linguistic equivalence of the scale. The second study group consists of 220 people. Data collected from this group were used in Exploratory Factor Analysis (EFA). The third study group consists of 230 people. Data collected from this group was used in Confirmatory Factor Analysis (CFA).

\section{Results}

Results on Language and Content Validity

In order to test the content validity of the scale, ten academicians were consulted. A minimum of five expert opinions is considered sufficient for the content validity of the scales (Lawshe, 1975). In order to decide whether an item should be included in the scale, it is sufficient 
for more than half of the experts to state that it is "necessary" for the relevant item (Alpar, 2014; Lawshe, 1975; Driver \& Maslakçı, 2020). It was concluded that the scale used in the research had content validity, since the majority of the academicians whose opinions were consulted in the study evaluated all the items as "necessary".

\section{Exploratory Factor Analysis (EFA)}

To test the reliability of the scale, Cronbach's alpha coefficient and Spearman-Brown reliability coefficient were examined. The Cronbach alpha coefficient of the scale is .78. The Spearman-Brown Reliability coefficient (split method) is .71. The study also looked at the correlation and item total statistics of the Positive Childhood Experiences Scale. Correlation coefficients of scale items and item-total statistical analysis results are given in table (Table 2). According to the results of the analysis, the correlation coefficients between the items were found to be between ,271 -,597. If the Cronbach alpha coefficient and the Spearman-Brown reliability coefficient are over .70, it is considered that the scale has a moderate level of reliability (Alpar, 2014; Müzezöztürk, 2013).

\section{Confirmatory Factor Analysis}

In confirmatory factor analysis, firstly, the values of goodness of fit were examined. Then, the factor structure was analyzed. In the study, the following model goodness fit were taken as a basis. These values are; $\chi 2$ / df (degrees of freedom), root mean square of estimation errors (Root Mean Square Error of Approximation-RMSEA), comparative fit index (CFI), excess fit index (Incremental Fit Index-IFI), goodness fit index (Goodness of Fit Index-GFI), the square root of the mean squares of error (Root Mean Square Residual-RMR) and the normed fit index (Normed Fit Index-NFI). Fit values before revision ( Chi-square / sd: 3.30, RMSEA: .079, NFI: .89, IFI: .92, CFI: .92, GFI: .95, RMR: .83). After looking at the goodness of fit indices, modification ( correction) indices were examined. In the study, necessary corrections were made based on the correction index values for covariances. In corrections for covariances, the variables in the model are combined with items that are perceived by the subjects as almost the same (Gürbüz, 2019). There are certain points that need to be considered when making corrections. These issues are; corrections are made one by one and no further corrections are made when the threshold values are reached. In addition, it is recommended not to make more than 2 corrections in the scales consisting of 6 to 11 items (Johnson, 2016; Meydan \& Şeşen, 2011). After the combination modifications of the PCES1-PCES3 items and the PCES5-PCES6 items in the scale were made, it was determined that the scale was within the expected goodness of fit values.

\section{Discussion \& Conclusion}


The aim of this study is to adapt the "Positive Childhood Experiences Scale", which consists of 7 items, developed by Bethell et al. (2019) and measures positive childhood experiences of individuals, into Turkish. It is evaluated that this scale, which has been adapted into Turkish, will fill a big gap in the field. Because, it is seen that there are a limited number of measurement tools measuring positive childhood experiences in our country and these measurement tools focus on a certain range of childhood (Akın et al., 2013; Doğan \& Aydın, 2020) or they measure childhood experiences more in the perspective of social relations (Manap, 2015). On the other hand, the Positive Childhood Experiences Scale, which was adapted, differs from other scales in that it is a measurement tool that covers the entire childhood -before the age of eighteen. The Cronbach's alpha value of the scale was calculated as .78. It was found that the single-factor PCES explained $45.22 \%$ of the total variance. In addition, factor loads of all scale items were found to be higher than .30 (Büyüköztürk, 2013). CFA was conducted with data obtained from 230 adults in order to determine whether the factor structure of the original form of PCES could be confirmed in the Turkish sample. The results showed that, as in EFA, the scale was unidimensional and the goodness of fit values were within acceptable limits. Therefore, it can be determined that there is no problem in the application of the Turkish adaptation of the Positive Childhood Experiences Scale and that it has sufficient validity and reliability. 
EK

\section{LÜTFEN}

Aşağıda verilen ifadeleri 18 yaşından önceki yaşantılarınıza/duygularınıza göre cevaplandırın.

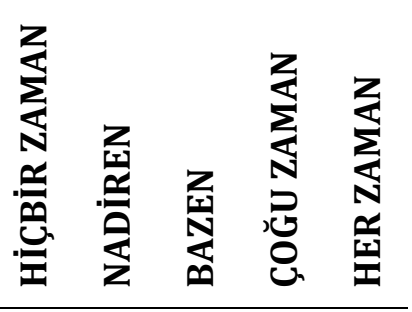

\begin{tabular}{llllll} 
Ailenizle, duygularınız hakkında hangi sıklıkta konuşabiliyordunuz? & $\mathbf{1}$ & $\mathbf{2}$ & $\mathbf{3}$ & $\mathbf{4}$ & $\mathbf{5}$ \\
\hline $\begin{array}{l}\text { Zor zamanlarda ailenizin yanınızda olduğunu hangi sıklıkta } \\
\text { hissediyordunuz? }\end{array}$ & $\mathbf{1}$ & $\mathbf{2}$ & $\mathbf{3}$ & $\mathbf{4}$ & $\mathbf{5}$ \\
\hline $\begin{array}{l}\text { Çocukluk döneminizin ne kadarında sizi evinizde güvende ve } \\
\text { korunmuş hissettiren bir yetişkin vardı? }\end{array}$ & $\mathbf{1}$ & $\mathbf{2}$ & $\mathbf{3}$ & $\mathbf{4}$ & $\mathbf{5}$ \\
\hline $\begin{array}{l}\text { Çevrenizde hangi sıklıkta anne ve babanızın dışında sizinle } \\
\text { gerçekten ilgilenen en az iki yetişkin oldu? }\end{array}$ & $\mathbf{1}$ & $\mathbf{2}$ & $\mathbf{3}$ & $\mathbf{4}$ & $\mathbf{5}$ \\
\hline $\begin{array}{l}\text { Arkadaşlarınız tarafından ne kadar sık desteklendiğinizi } \\
\text { hissediyordunuz? }\end{array}$ & $\mathbf{1}$ & $\mathbf{2}$ & $\mathbf{3}$ & $\mathbf{4}$ & $\mathbf{5}$ \\
\hline $\begin{array}{l}\text { Hangi sıklıkta kendinizi okuduğunuz liseye ait hissediyordunuz? } \\
\text { Geleneksel ve toplu etkinliklere katılmaktan hangi sıklıkta keyif }\end{array}$ & $\mathbf{1}$ & $\mathbf{2}$ & $\mathbf{3}$ & $\mathbf{4}$ & $\mathbf{5}$ \\
\hline \begin{tabular}{l} 
alırdınız? \\
\hline
\end{tabular} & $\mathbf{1}$ & $\mathbf{3}$ & $\mathbf{4}$ & $\mathbf{5}$ \\
\hline
\end{tabular}

\section{Notlar.}

1. Ölçek, tek boyutlu olup toplam puan üzerinde değerlendirilmektedir. Ölçekte tersten kodlanan madde bulunmamaktadır. Ölçekten alınan yüksek puanlar, bireyin olumlu çocukluk yaşantılarının fazla olduğunu göstermektedir. Ölçek, 18 yaşından büyük kişilere uygulanmaktadır.

2. Bu ölçeğin yazarları, yazarlara atıfta bulunmak kaydıyla ölçeğin sadece akademik amaçla kullanılmasına izin verirler. 